\title{
A New Method to Calculate the Pure Component Parameters of Any Two-Parameter Equation of State
}

\author{
Isam H. Aljundi ${ }^{1,2}$ \\ ${ }^{1}$ Chemical Engineering Department, University of Nizwa, Nizwa 616, Oman \\ ${ }^{2}$ Chemical Engineering Department, Mutah University, Al-Karak 61710, Jordan
}

Correspondence should be addressed to Isam H. Aljundi, aljundi@unizwa.edu.om

Received 14 June 2011; Accepted 8 August 2011

Academic Editor: Mohammad Al-Nimr

Copyright ( 2011 Isam H. Aljundi. This is an open access article distributed under the Creative Commons Attribution License, which permits unrestricted use, distribution, and reproduction in any medium, provided the original work is properly cited.

Reliable equations of state are very important in the design of refrigeration cycles, since thermodynamic properties can be calculated by simple differentiation. In this paper, a new method to calculate the parameters of any two-parameter equation of state is presented. The method is based on the use of Clapeyron equation and the experimental PVT data. This method was tested on a newly developed cubic equation of state and proved to be simple and fast. Results showed orders of magnitude enhancement in prediction of the saturated vapor pressure even near the critical region. The Percent Absolute Average Deviation (\%AAD) was always less than 0.1 in the studied cases. It also showed that the parameters calculated using the original equation deviate strongly from the "experimental" values as the temperature decreases below the critical point. This method can be used to redefine the temperature dependences of these parameters and develop new mixing rules for the mixtures.

\section{Introduction}

The refrigeration industry continues to undergo major changes as older refrigerants with high ozone depletion potential (ODP), primarily chlorofluorocarbons (CFCs) and hydrochlorofluorocarbons (HCFCs), are replaced with newer refrigerants such as hydrofluorocarbons (HFCs) [1]. Since the HFCs have relatively large global warming potentials (GWPs) as compared to natural refrigerants, the search is still going for the next-generation refrigerants [2-4]. Hydrocarbons are one of the candidates for refrigerants of next generation heat pump and refrigeration systems. The hydrocarbons, which have zero GWP, have superior thermophysical properties as a refrigerant to fluorocarbons and are widely used in domestic refrigerators.

When selecting a fluid as a refrigerant, the vapor pressure curves of possible alternatives is what is first investigated. Accurate vapor pressure data are important for the design of process equipment especially in the field of refrigeration and air conditioning.

Experimental vapor pressure data, which cover the entire vapor pressure range, are very rare [5]. In addition, the design of refrigeration cycles requires accurate knowledge of the thermodynamic properties of pure and mixture refrigerants. Although there are a large body of experimental data on refrigerants in the literature, the amount of experimental data are still incomplete and different data sets are usually inconsistent [6].

One of the major tasks of thermodynamics is the description of all functions with the highest accuracy. For this purpose fundamental multiparameter equations of state (EoS) have been developed. From these any thermodynamic function can be derived by simple mathematical differentiation [7].

Originally, equations of state were used mainly for pure components [8]. Later on, they were used for mixtures. The mixture parameters are defined by mixing and combining rules using the pure component parameters. As a result, a technique must be devised to obtain pure component parameters for use in the equation of state before mixing and combining rules are tested.

In general, cubic equations of state have the following form [9]:

$$
Z=\frac{P \underline{V}}{R T}=\frac{1+m \eta}{1-n \eta}-\frac{4 \theta \eta}{T^{\xi}\left(1+4 b_{1} \eta\right)\left(1+4 b_{2} \eta\right)},
$$




$$
\begin{gathered}
\theta=\frac{a}{b R T}, \\
\eta=\frac{b}{4 \underline{V}} .
\end{gathered}
$$

The simplest method used to calculate the parameters ( $a$ and $b$ ) is to solve the thermodynamic critical point criteria for a pure material:

$$
\left(\frac{\partial P}{\partial \underline{V}}\right)_{T=T_{c}}=\left(\frac{\partial^{2} P}{\partial \underline{V}^{2}}\right)_{T=T_{c}}=0
$$

In the van der Waals equation of state, it is assumed that the parameters as calculated at the critical point are applicable at any temperature. However, to obtain better agreement with the experimental data, the parameters should be modified and make temperature dependent.

An alternative method of calculation presented by Panagiotopulos and Kumar [10] made use of the vapor pressure, the saturated liquid molar volume, and the phase equilibrium criterion between the liquid and vapor phases: equality of the fugacities. It involves the solution of a system of three nonlinear equations with four unknowns. One degree of freedom will be eliminated by using the liquid compressibility from the experimental data.

In this work a new method will be presented to calculate the pure component parameters for any two-parameter equation of state directly from the experimental data. A general equation of state for fluids recently derived by Dashtizadeh et al. [9] based on perturbation theory will be used as an example of this type of equations.

\section{The Model}

Choosing $m=n=4, \xi=b_{1}=0$, and $b_{2}=1$, (1) is changed to

$$
Z=\frac{\underline{V}+b}{\underline{V}-b}-\frac{a}{R T(\underline{V}+b)} .
$$

By imposing the critical point criterion, parameters $a$ and $b$ at the critical point are found as

$$
\begin{aligned}
a_{c} & =0.47448 \frac{R^{2} T_{c}^{2}}{P_{c}}, \\
b_{c} & =0.06824 \frac{R T_{c}}{P_{c}} .
\end{aligned}
$$

Then a correction was made to the parameters and made temperature and acentric factor dependent

$$
\begin{aligned}
& a=a_{c} \alpha\left(T_{r}, \omega\right), \\
& b=b_{c} \beta\left(T_{r}, \omega\right) .
\end{aligned}
$$

To satisfy the critical point criteria, $\alpha\left(T_{r}, \omega\right)$ and $\beta\left(T_{r}, \omega\right)$ must equal unity at the critical point, therefore

$$
\begin{gathered}
\alpha\left(T_{r}, \omega\right)=\left[1+m_{1}\left(1-T_{r}\right)+m_{2}\left(1-T_{r}\right)^{2}+m_{3}\left(1-T_{r}\right)^{3}\right]^{2}, \\
\beta\left(T_{r}, \omega\right)=1+n\left(1-T_{r}\right), \\
m_{1}=0.2513+0.4178 \omega-0.0207 \omega^{2}, \\
m_{2}=-0.1382-0.5923 \omega-1.0493 \omega^{2}, \\
m_{3}=0.1931+1.3955 \omega+0.1961 \omega^{2}, \\
n=0.2155-0.9069 \omega-0.206 \omega^{2} .
\end{gathered}
$$

The technique discussed below make use of Clapeyron equation:

$$
\frac{\mathrm{d} P}{\mathrm{~d} T}=\frac{\Delta_{\mathrm{trs}} S}{\Delta_{\mathrm{trs} \underline{V}}},
$$

where $\Delta_{\mathrm{trs}} S$ and $\Delta_{\mathrm{trs}} \underline{V}$ are the entropy and volume of transition. The Clapeyron equation is an exact expression for the slope of the phase boundary and applies to any phase equilibrium of any pure substance [17]. When applied to the liquid vapor boundary, the entropy of vaporization at a temperature $T$ is equal to $\Delta_{\text {vap }} H / T$; the Clapeyron equation for the liquid-vapor boundary is therefore

$$
\frac{\mathrm{d} P}{\mathrm{~d} T}=\frac{\Delta_{\mathrm{vap}} H}{T \Delta_{\mathrm{vap}} \underline{V}},
$$

where $\Delta_{\operatorname{vap}} \underline{V}=\underline{V}^{V}-\underline{V}^{L}$ and the vapor molar volume is calculated from the equation of state as

$$
\underline{V}^{V}=\frac{R T}{P}\left[\frac{V^{V}+b}{\underline{V}^{V}-b}-\frac{a}{R T\left(\underline{V}^{V}+b\right)}\right]
$$

substitution of (16) into (15) will result:

$$
\frac{R T}{P}\left[\frac{\underline{V}^{V}+b}{\underline{V}^{V}-b}-\frac{a}{R T\left(\underline{V}^{V}+b\right)}\right]-\underline{V}^{L}=\frac{\Delta_{\mathrm{vap}} H}{T(\mathrm{~d} P / \mathrm{d} T)} .
$$

In addition, when $\underline{V}=\underline{V}^{L}$, the equation of state becomes

$$
\frac{P \underline{V}^{L}}{R T}=\frac{V^{L}+b}{\underline{V}^{L}-b}-\frac{a}{R T\left(\underline{V}^{L}+b\right)} .
$$

If $P V T$ experimental data is available at saturation, then a simultaneous solution of (18) along with the Clapeyron equation, Equation (17), will result in the "experimental" values of the parameters $a$ and $b$.

The enthalpy change of vaporization can be calculated from the departure function [18]:

$$
\begin{aligned}
\underline{H}(T, P)-\underline{H}^{I G}(T, P)= & R T(Z-1) \\
& +\int_{\infty}^{\underline{V}}\left[T\left(\frac{\partial P}{\partial T}\right)_{\underline{V}}-P\right] d \underline{V} .
\end{aligned}
$$


TABle 1: Percent absolute average deviation for the saturated vapor pressure.

\begin{tabular}{|c|c|c|c|c|c|}
\hline Species & $\% \mathrm{AAD}^{\mathrm{a}}$ using original parameters & \%AAD using parameters based on the new method & Temperature range $(\mathrm{K})$ & $n$ & Reference \\
\hline Argon & 0.34 & 0.16 & $84-156$ & 23 & {$[11]$} \\
\hline i-butane & 1.2 & 0.02 & $260-340$ & 10 & {$[12]$} \\
\hline n-butane & 1.2 & 0.01 & $270-340$ & 10 & {$[12]$} \\
\hline Ethane & 0.61 & 0.09 & $185-303$ & 19 & {$[13]$} \\
\hline Propane & 0.9 & 0.01 & $190-340$ & 17 & {$[12]$} \\
\hline Propylene & 1.3 & 0.04 & $230-340$ & 12 & [12] \\
\hline $\mathrm{SF}_{6}$ & 0.8 & 0.03 & $224-314$ & 24 & {$[14]$} \\
\hline
\end{tabular}

${ }^{\mathrm{a}}$ Percent Average Absolute Deviation, \%AAD $=(100 \% / n) \sum_{1}^{n}\left|\left(P^{\text {cal }}-P^{\exp }\right) / P^{\exp }\right|$.

TABLE 2: Percent absolute average deviation for the enthalpy change of vaporization.

\begin{tabular}{lccc}
\hline Species & \%AAD ${ }^{\text {a }}$ using original parameters & \%AAD using parameters based on the new method & Experimental data reference \\
\hline Argon & 3.72 & 4.82 & {$[15]$} \\
i-butane & 1.06 & 6.99 & {$[16]$} \\
n-butane & 1.02 & 9.01 & {$[15]$} \\
Ethane & 8.86 & 10.74 & {$[15]$} \\
Propane & 2.70 & 9.90 & {$[15]$} \\
Propylene & 5.35 & 9.95 & {$[15]$} \\
$\mathrm{SF}_{6}$ & 12.50 & 14.39 & {$[16]$} \\
\hline
\end{tabular}

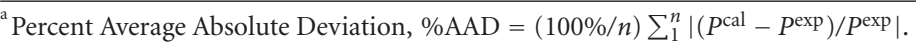

Substituting for the derivatives in (19), the enthalpy departure function becomes

$$
\begin{aligned}
\underline{H}-\underline{H}^{I G}= & R T(Z-1)+\frac{1}{b}\left(T \frac{\mathrm{d} a}{\mathrm{~d} T}-a-\frac{a T}{b} \frac{\mathrm{d} b}{\mathrm{~d} T}\right) \ln \left(1+\frac{B}{Z}\right) \\
& -2 P T \frac{\mathrm{d} b / \mathrm{d} T}{Z-B}+\frac{a P}{R b} \frac{\mathrm{d} b / \mathrm{d} T}{Z+B},
\end{aligned}
$$

where $B=b P / R T$.

Following this procedure, experimental phase equilibrium data can be reproduced exactly using simple equations without calculating fugacities. In addition, the dependence of parameters $a$ and $b$ on temperature can be determined and analyzed directly using the experimental data with no assumptions.

\section{Results and Discussion}

Data for seven species was used to investigate the validity of this procedure, and the experimental parameters were compared with those obtained by Dashtizadeh et al. equation of state. The experimental and calculated parameters for these species are shown in Figures 1 and 2.

An overall look at these figures shows that there is a difference, and the difference increases as temperature decreases below the vicinity of the critical region.

The results of calculating the vapor pressure using the experimental parameters showed that the prediction capability of the vapor pressure enhanced appreciably as shown in Table 1.

The dependencies of parameter $a$ and $b$ on temperature were also studied. As expected, the parameters showed significant temperature dependence. The difference between the calculated and experimental values of the parameter $a$ increased as the temperature decreased below the critical point. This is expected since the calculated parameters must satisfy the critical point condition. However, the experimental and calculated values converged to the same value not exactly at the true critical point but near the critical point. This shift in the critical point is due to the difference between the true critical compressibility factor and the one predicted by the equation of state, $Z_{c}=0.333$, which is overestimated since the true critical compressibility for different hydrocarbons varies from 0.24 to 0.29 [8].

Almost linear relationship was found with temperature for the studied systems; as shown from the experimental values of $b$, while the calculated values from the original equation of state deviate strongly as the temperature decreases below the critical point.

This suggests that the proposed functionality of temperature could be redefined based on this method of calculation to get more accurate prediction of the PVT data.

On the other hand, the enthalpy change of vaporization was also calculated using the original parameters, and the parameters calculated using the proposed method and compared with the experimental data as shown in Table 2. Although some of the investigated species-such as simple molecules (Argon), hydrocarbon (Ethane), and nonhydrocarbon $\left(\mathrm{SF}_{6}\right)$ - showed comparable results with that calculated using the original parameters, others showed larger deviations. Accuracy of the experimental data and the dependency of departure functions on the derivatives of parameters $a$ and $b$ play a significant role in such a calculation. 


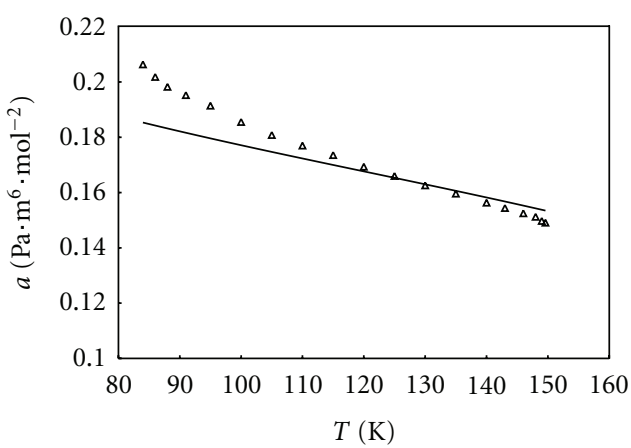

(a)

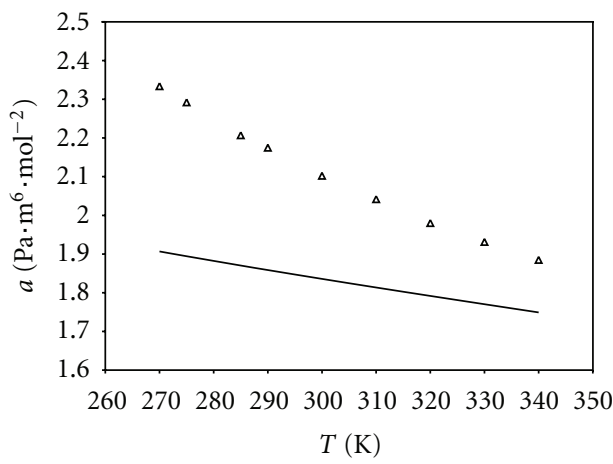

(c)

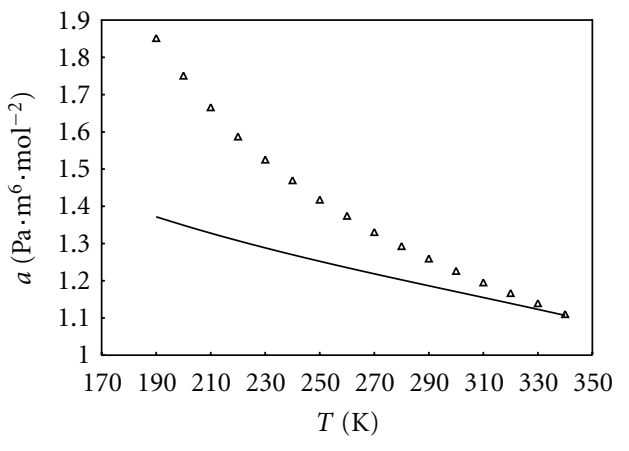

(e)

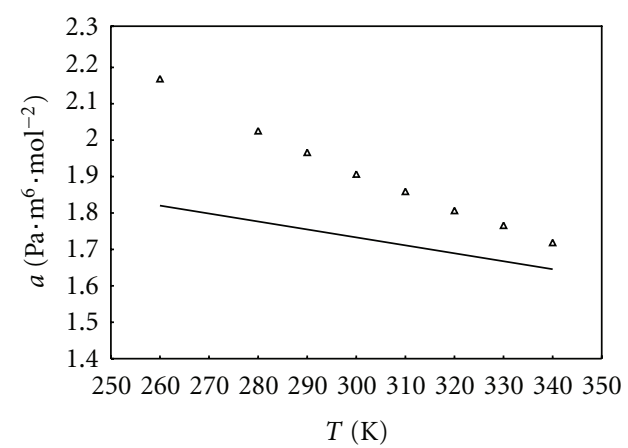

(b)

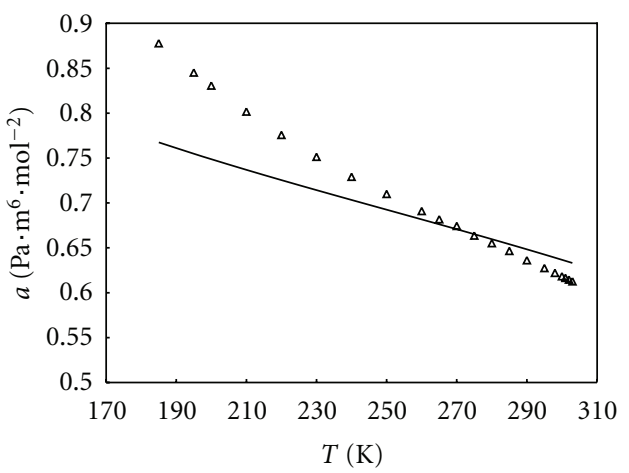

(d)

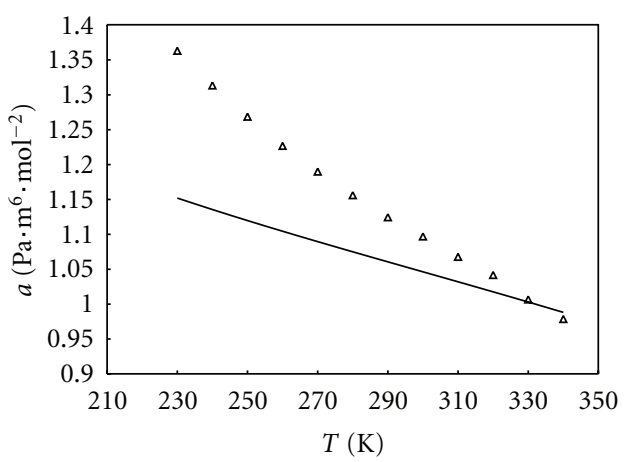

(f)

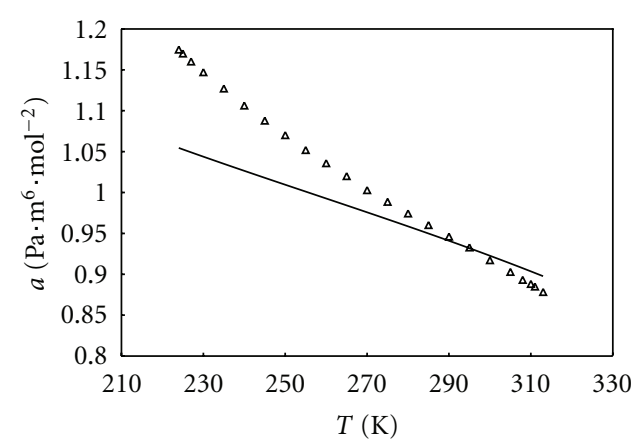

(g)

Figure 1: Attraction parameter of (a) Argon, (b) i-butane, (c) n-butane, (d) Ethane, (e) Propane, (f) Propylene, (g) Sulphur hexafluoride; $\Delta$ : experimental value using the new method; - : calculated from (6). 


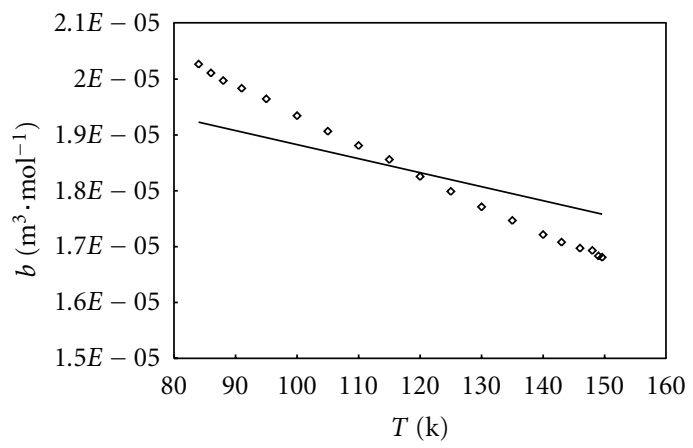

(a)

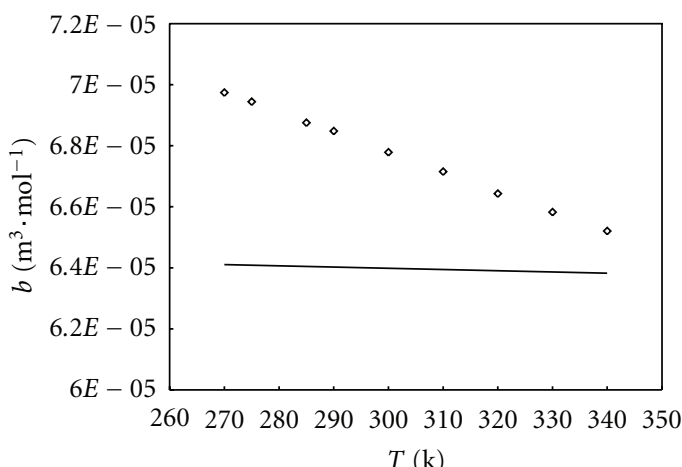

(c)

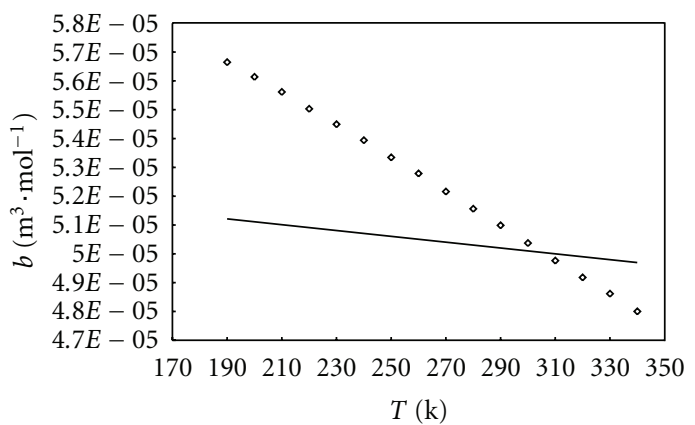

(e)

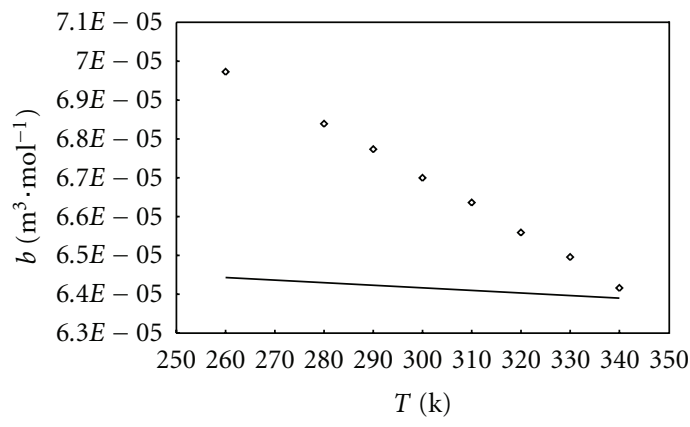

(b)

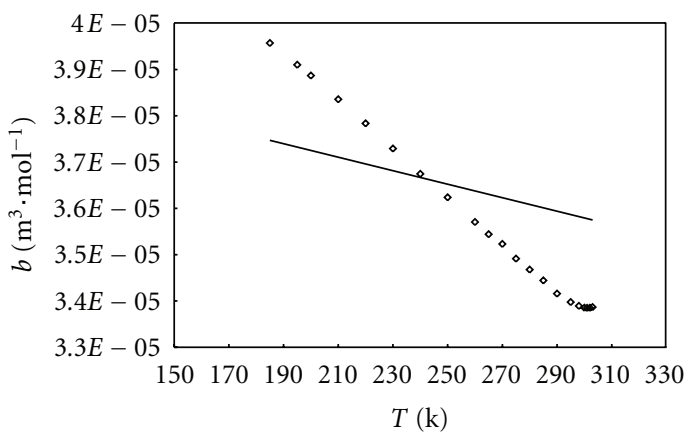

(d)

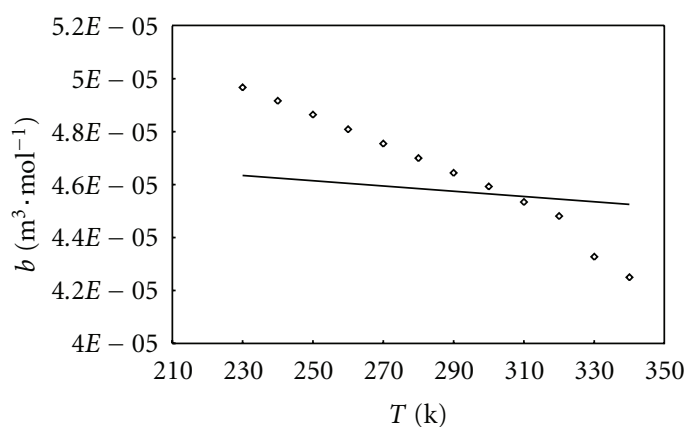

(f)

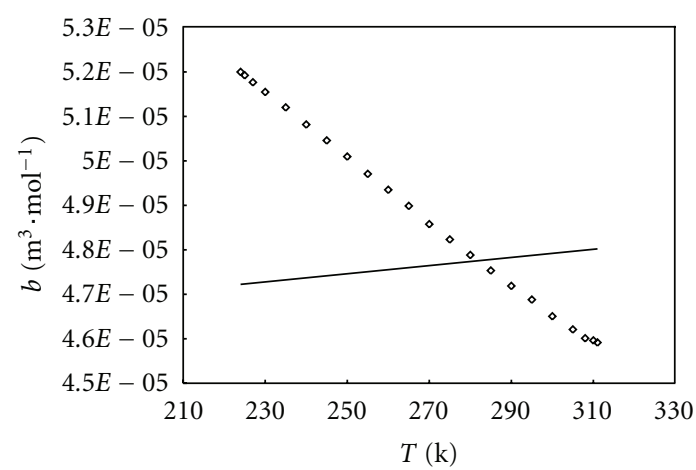

(g)

Figure 2: Covolume parameter of (a) Argon, (b) i-butane, (c) n-butane, (d) Ethane, (e) Propane, (f) Propylene, (g) Sulphur hexafluoride; $\diamond$ : experimental value using the new method; - calculated from (7). 


\section{Conclusions}

A new simple method was proposed to calculate the parameters of any two-parameter equation of state. This method is based on the use of Clapeyron equation along with the experimental PVT data. Test on seven species showed that the prediction of the saturated vapor pressure was enhanced in orders of magnitude for most of it. Enthalpy change of vaporization showed comparable results for some of the studied species, while others showed larger deviations.

It is strongly believed that this method will result in developing new mixing rules since it will allow for the use of experimental data rather than optimized parameters. It will also allow the development of more accurate functions of temperature for these parameters.

\section{Nomenclature}

a: Attraction parameter $\left(\mathrm{Pa} \cdot \mathrm{m}^{6} \cdot \mathrm{mol}^{-2}\right)$

$b$ : Molar covolume $\left(\mathrm{m}^{3} \cdot \mathrm{mol}^{-1}\right)$

$b_{i}$ : Parameters of (1)

$B$ : Dimensionless molar covolume parameter

$H$ : Enthalpy $\left(\mathrm{J} \cdot \mathrm{mol}^{-1}\right)$

$m_{i}$ : Parameters in (8)

$n:$ Parameter in (9)

P: $\quad$ Pressure $(\mathrm{Pa})$

$R: \quad$ Universal gas constant $\left(\mathrm{J} \cdot \mathrm{mol}^{-1} \cdot \mathrm{K}^{-1}\right)$

S: $\operatorname{Entropy}\left(\mathrm{J} \cdot \mathrm{mol}^{-1} \cdot \mathrm{K}^{-1}\right)$

$T$ : Temperature $(\mathrm{K})$

$\underline{V}$ : Molar volume $\left(\mathrm{m}^{3} \cdot \mathrm{mol}^{-1}\right)$

$Z$ : Compressibility factor.

\section{Greek Letters}

$\eta$ : Packing factor

$\theta$ : Parameter in (1)

$\omega$ : Pitzer acentric factor

$\xi$ : Parameter in (1)

$\Delta$ : Change.

\section{Subscripts}

c: Critical

$r$ : Reduced

trs: Transition

vap: Vaporization.

\section{Superscripts}

IG: Ideal gas

L: Liquid

$V$ : Vapor.

\section{References}

[1] J. S. Brown, "Predicting performance of refrigerants using the Peng-Robinson Equation of State," International Journal of Refrigeration, vol. 30, no. 8, pp. 1319-1328, 2007.
[2] D. B. Bivens and B. H. Minor, "Fluoroethers and other next generation fluids," International Journal of Refrigeration, vol. 21, no. 7, pp. 567-576, 1998.

[3] T. Rachidi, A. Bernatchou, M. Charia, and H. Loutfi, "New fluids as substitute refrigerants for R12," Solar Energy Materials and Solar Cells, vol. 46, no. 4, pp. 333-347, 1997.

[4] S. Devotta, S. Gopichand, and V. R. Pendyala, "Assessment of HFCs, fluorinated ethers and amine as alternatives to CFC12," International Journal of Refrigeration, vol. 16, no. 2, pp. 84-90, 1993.

[5] E. D. Rogdakis and P. A. Lolos, "Simple generalized vapour pressure- and boiling point correlation for refrigerants," International Journal of Refrigeration, vol. 29, no. 4, pp. 632-644, 2006.

[6] H. Eslami, "An analytical equation of state for refrigerants," International Journal of Refrigeration, vol. 27, no. 6, pp. 649655, 2004.

[7] L. Piazza, G. Scalabrin, P. Marchi, and D. Richon, "Enhancement of the extended corresponding states techniques for thermodynamic modeling. I. Pure fluids," International Journal of Refrigeration, vol. 29, no. 7, pp. 1182-1194, 2006.

[8] Y. S. Wei and R. J. Sadus, "Equations of state for the calculation of fluid-phase equilibria," AIChE Journal, vol. 46, no. 1, pp. 169-196, 2000.

[9] A. Dashtizadeh, G. R. Pazuki, V. Taghikhani, and C. Ghotbi, "A new two-parameter cubic equation of state for predicting phase behavior of pure compounds and mixtures," Fluid Phase Equilibria, vol. 242, no. 1, pp. 19-28, 2006.

[10] A. Z. Panagiotopoulos and S. K. Kumar, "A generalized technique to obtain pure component parameters for two-parameter equations of state," Fluid Phase Equilibria, vol. 22, no. 1, pp. 77-88, 1985.

[11] R. Gilgen, R. Kleinrahm, and W. Wagner, "Measurement and correlation of the (pressure, density, temperature) relation of argon II. Saturated-liquid and saturated-vapour densities and vapour pressures along the entire coexistence curve," The Journal of Chemical Thermodynamics, vol. 26, no. 4, pp. 399-413, 1994.

[12] S. Glos, R. Kleinrahm, and W. Wagner, "Measurement of the $(\mathrm{p}, \rho, \mathrm{T})$ relation of propane, propylene, $\mathrm{n}$-butane, and isobutane in the temperature range from (95 to 340 ) $\mathrm{K}$ at pressures up to $12 \mathrm{MPa}$ using an accurate two-sinker densimeter," Journal of Chemical Thermodynamics, vol. 36, no. 12, pp. 10371059, 2004.

[13] M. Funke, R. Kleinrahm, and W. Wagner, "Measurement and correlation of the $(\mathrm{p}, \rho, \mathrm{T})$ relation of ethane I. The homogeneous gas and liquid regions in the temperature range from 95 $\mathrm{K}$ to $340 \mathrm{~K}$ at pressures up to $12 \mathrm{MPa}$," Journal of Chemical Thermodynamics, vol. 34, no. 12, pp. 2001-2015, 2002.

[14] M. Funke, R. Kleinrahm, and W. Wagner, "Measurement and correlation of the $(\mathrm{p}, \rho, \mathrm{T})$ relation of sulphur hexafluoride (SF6). II. Saturated-liquid and saturated-vapour densities and vapour pressures along the entire coexistence curve," Journal of Chemical Thermodynamics, vol. 34, no. 6, pp. 735-754, 2002.

[15] R. Perry, D. Green, and J. Maloney, Perry's Chemical Engineer's Handbook, McGraw Hill, 7th edition, 1997.

[16] B. Poling, J. Prausnitz, and J. O'connell, The Properties of Gases and Liquids, McGraw Hill, 5th edition, 2001.

[17] P. Atkins and J. de Paula, Atkins' Physical Chemistry, Oxford University Press, 7th edition, 2002.

[18] S. Sandler, Chemical, Biochemical, and Engineering Thermodynamics, John Wiley, 4th edition, 2006. 

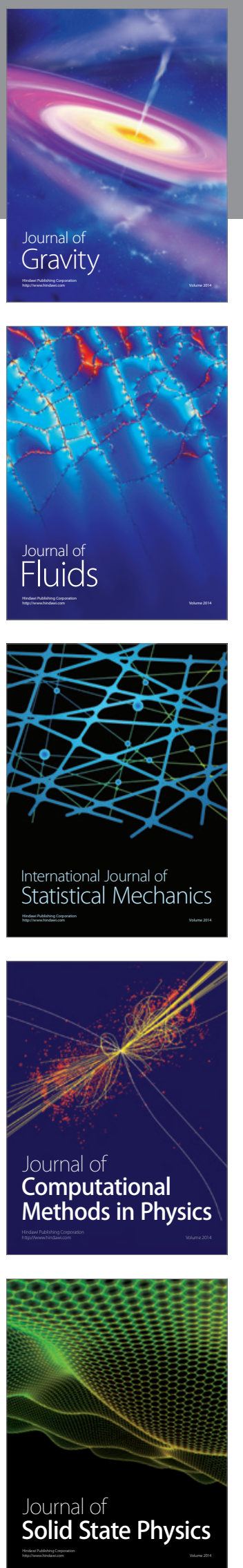

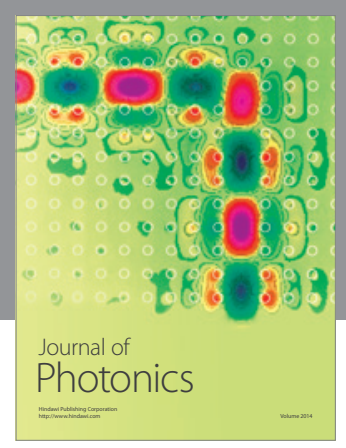

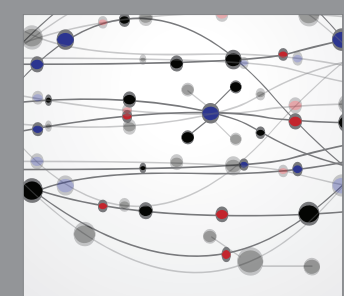

The Scientific World Journal
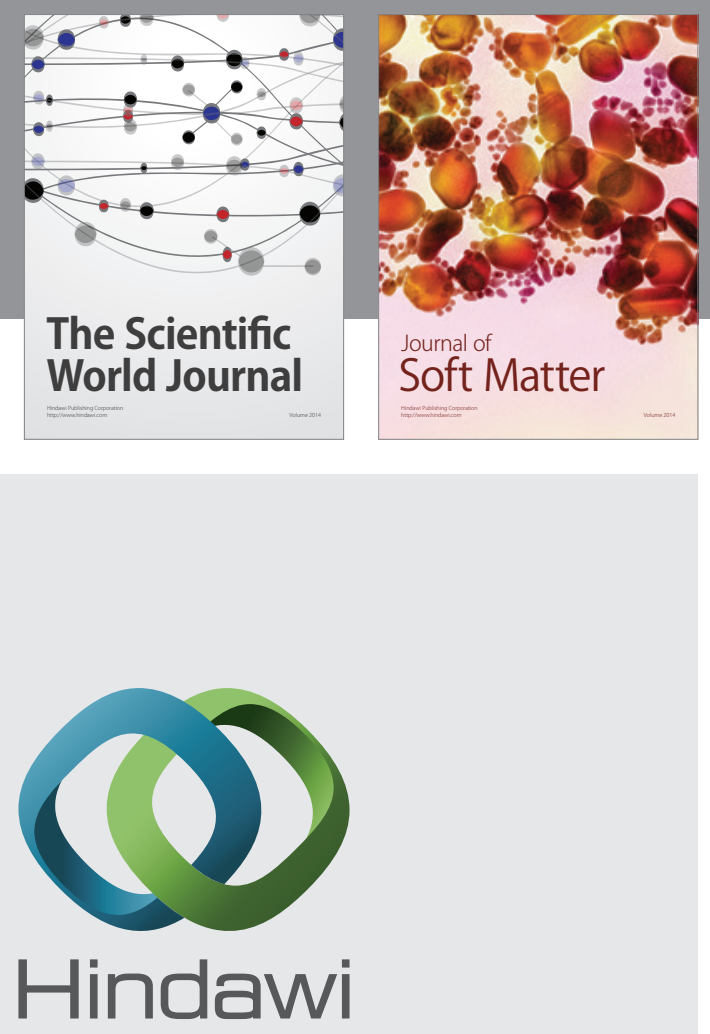

Submit your manuscripts at

http://www.hindawi.com
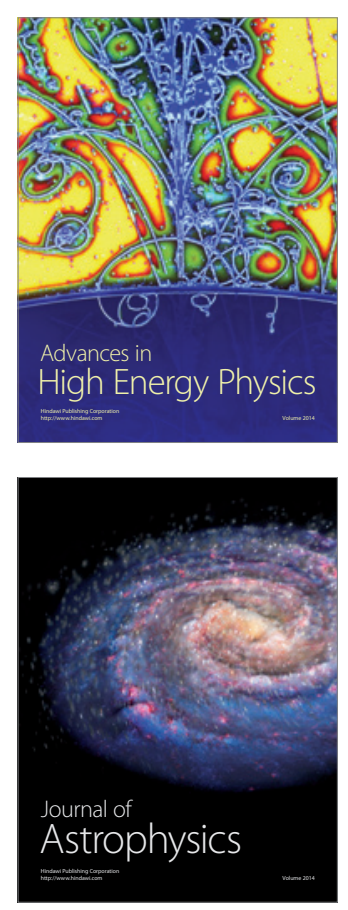
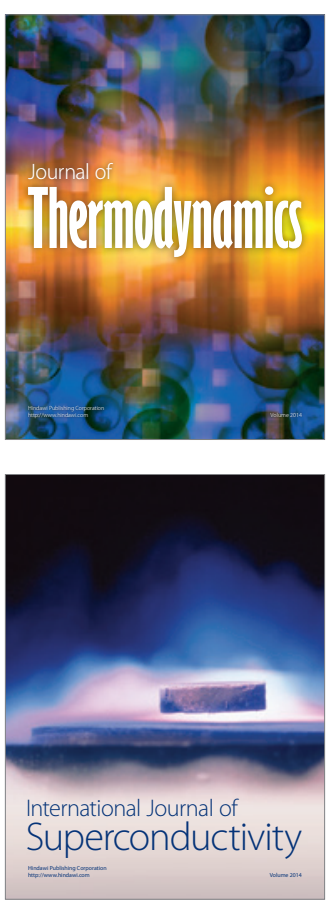
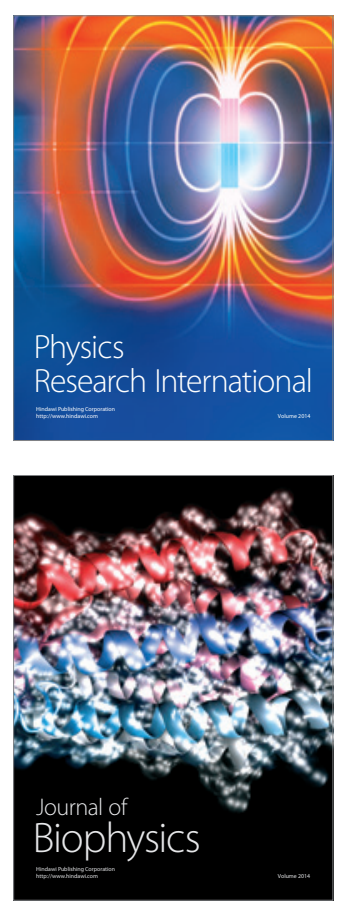
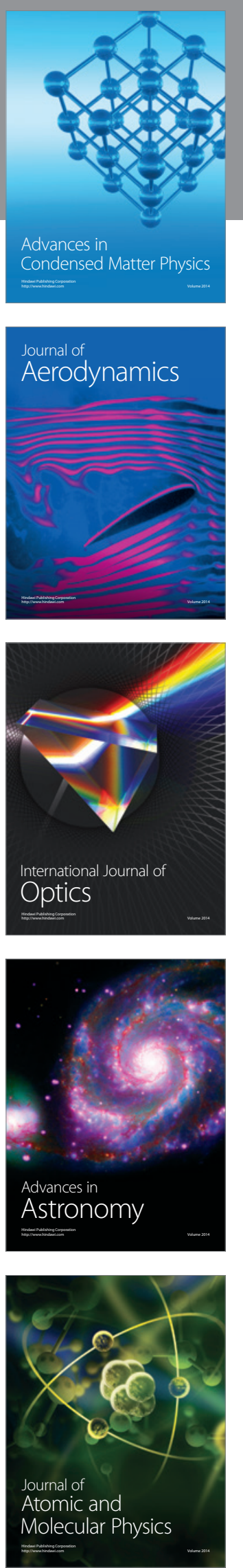